\title{
Formation of soot in the disposal of municipal solid waste
}

\author{
Olga Barysheva ${ }^{1[0000-0002-5014-7540] *}$, and Alina Mokhova1[0000-0002-4966-6693] \\ ${ }^{1}$ Kazan State University of Architecture and Engineering, 420043 Kazan, Russia
}

\begin{abstract}
In power plants intended for the disposal of solid household waste, the processes take place at a high temperature. For such installations, nonequilibrium processes are characteristic of a change in the composition of combustion products caused by the final rates of the ongoing chemical reactions. This affects the basic characteristics of the combustion process of municipal solid waste. A mathematical model has been created for calculating the chemically nonequilibrium composition of the fuel. Solid household and industrial waste is a high-energy fuel. It is a high energy fuel. The process of thermal neutralization of solid household waste is considered. An alternative calculation method is presented that allows one to find the composition of combustion products under conditions of nonequilibrium in the process of thermal utilization of solid domestic waste. The data on the composition and properties of solid household waste obtained by the developed method of calculation allow predicting the yield of super Eco toxicants in combustion products. On the basis of the equations of formal chemical kinetics, an alternative was created, which consists in determining the composition of combustion products taking into account the kinetics of chemical reactions. The assumption is introduced that transformations in the gas phase are elementary, one-stage. Various chemical interactions can be represented by a set of elementary stages. The most probable are mono-, biand three molecular chemical reactions. The method allows predicting the yield of Eco toxicants by finding the composition of the fuel combustion products prior to its utilization.
\end{abstract}

Keywords. Nonequilibrium processes, chemical kinetics, equilibrium, composition, municipal solid waste.

\section{Introduction}

The rate of formation of soot particles directly depends on the molecular weight of saturated and unsaturated hydrocarbons. The higher the molecular weight of the substance, the higher it is. Consequently, soot formation is associated with the properties of the fuel under study. There is a direct relationship between the ratio of hydrogen to carbon and the concentration of soot. The higher the $H / C$ ratio, the higher the concentration of soot particles [1-4].

*Corresponding author: obbars@gmail.com 
In many power plants designed for thermal waste disposal, there is a problem of components not burning out. The burnout rate of incomplete combustion products is higher than the burnup rate of soot during thermal utilization of municipal solid waste [5-8].

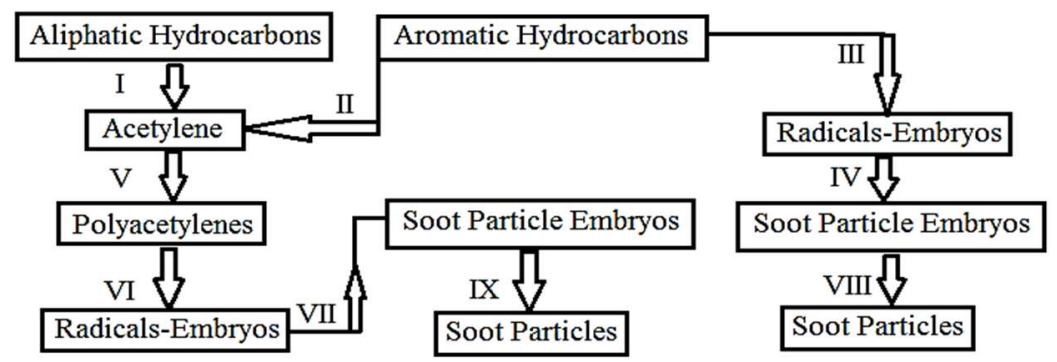

Fig. 1. Soot formation diagram.

Let us consider a model of the formation of soot particles by a radical chain process. First, the formation of nucleated radicals occurs.

$$
\mathrm{C}_{n} \mathrm{H}_{m} \rightarrow \mathrm{C}_{2} \mathrm{H}_{2} \rightarrow \mathrm{C}_{4} \mathrm{H}_{4} \rightarrow \mathrm{C}_{4} \mathrm{H}_{2} \rightarrow \mathrm{C}_{6} \mathrm{H}_{2} \rightarrow \mathrm{C}_{8} \mathrm{H}_{12} \rightarrow \ldots \rightarrow \text { soot }
$$

Further, nuclei from nucleated radicals are formed, and finally, the growth of soot particles from nuclei occurs. Fig. 1 shows a diagram of soot formation in flames of hydrocarbon fuels.

Table. Individual stages of soot formation.

\begin{tabular}{|c|l|}
\hline Stage & \multicolumn{1}{|c|}{ Description of processes } \\
\hline I, II & $\begin{array}{l}\text { The initial hydrocarbons in the flame undergo pyrolysis, the products of which are low } \\
\text { molecular weight hydrocarbons. }\end{array}$ \\
\hline III & $\begin{array}{l}\text { Aromatic hydrocarbons at temperatures below } 1750 \ldots 1800 \mathrm{~K} \text { form radicals with an } \\
\text { aromatic structure in the flame. }\end{array}$ \\
\hline IV, VII & $\begin{array}{l}\text { Hydrocarbon radicals and low molecular weight hydrocarbons attach to the nucleus } \\
\text { radicals, resulting in the formation of soot nuclei. }\end{array}$ \\
\hline V, VI. & $\begin{array}{l}\text { Acetylene polymerization occurs according to the following mechanism: } \\
C_{2} H_{2} \rightarrow C_{4} H_{3} \rightarrow C_{4} H_{2} \rightarrow C_{6} H_{2} \rightarrow C_{10} H_{2} \rightarrow \ldots . \\
\text { More complex structures radical-nuclei are formed. }\end{array}$ \\
\hline VIII, IX & In a heterogeneous hydrocarbon decomposition reaction, the growth of soot particles occurs. \\
\hline
\end{tabular}

Table shows the individual stages of the formation of soot particles, acetylene is considered. Other low molecular weight hydrocarbons interact with soot particles in the same way.

The purpose of the research is forecasting the yield of soot during thermal disposal of construction waste, waste from medical enterprises or organizations associated with the chemical industry, etc.

\section{Method}

\subsection{Calculated Model of Soot Formation}

Let us present a calculation method for the process of soot formation, which occurs with the formation of nucleated radicals. The rate of formation of radical nuclei is found from the equation:

$$
\frac{d n}{d \tau}=n_{0}+(f-g) n-g_{0} N_{s} n,
$$


where $n_{0}$ - the rate of spontaneous nucleation of radical-nuclei; $n$ - quantitative concentration of nucleated radicals; $f$ - branching ratio; $g$ - line break factor, $g_{0}$ - coefficient of uptake of nucleated radicals by soot particles; $N_{s}$ - volumetric number of soot particles.

The product of the volumetric number of soot particles and the quantitative concentration of nucleated radicals reflects the death of active soot particles on the soot surface $[9,10]$.

The rate of soot formation depends on the interaction of nucleated radicals with the starting carbon molecules [11]. It also depends on the process of capture of nucleated radicals by soot particles. This process inhibits the formation of new particles. The rate of formation of soot particles is found by the formula:

$$
\frac{d N_{s}}{d \tau}=\left(a-b N_{s}\right) n
$$

where $a$ and $b$ - coefficients, the relationship of which is determined by the expression $a=b N_{\max }$.

Coefficients $-(f-g), g_{0}, a$ in equations (2.1) and (2.2) depend on the specific combustion conditions.

To obtain the time dependence of the formation of the volume number of soot particles, it is necessary to solve jointly equations $(2.1)$ and $(2.2)[12,13]$.

The induction period of the soot formation process is determined by $1 / a$. Let us assume that the first nucleus radicals are formed as a result of a monomolecular reaction of hydrogen decomposition [14]. Let us write down an expression for determining the rate of spontaneous nucleation of radical-nuclei:

$$
n_{0}=10^{13} N e^{-E /(R T)},
$$

where $E$-dissipation rate of turbulent kinetic energy; $N$ - number of hydrocarbon molecules per unit volume; $10^{13}$ - vibration frequency of atoms in a molecule along a broken bond.

The fuel burnup rate in the turbulent combustion model is found from the expression:

$$
\frac{d C_{T}}{d \tau}=A \overline{C_{T}} \frac{E}{K}
$$

where $K$-turbulent kinetic energy; $\overline{C_{T}}$ - time-average fuel mass concentration; $A$ - constant depending on the structure of the flame and the kinetics of the chemical reaction description of the fuel.

For areas of a mixture with a low oxygen concentration, the fuel burnup rate is found from the dependence:

$$
\frac{d C_{T}}{d \tau}=A \frac{\overline{C_{O_{2}}} E}{L_{0} K}
$$

where $\overline{C_{O_{2}}}$ - time-average mass concentration of oxygen.

The fuel burnup rate for turbulent flames of homogeneous mixtures is found by the formula:

$$
\frac{d C_{T}}{d \tau}=A B \frac{\overline{C_{p r}} E}{\left(1+L_{0}\right) K}
$$

where $\overline{C_{p r}}$ - time-average mass concentration of combustion products; $B$ - constant.

For the computational model of turbulent combustion, the reaction rate is determined by its minimum value for fuel burnout:

$$
\left\{\begin{aligned}
\frac{d C_{v}}{d \tau}=n_{0} & +\left(f-g_{0}\right) n-g_{0} N_{s} n \\
n_{0} & =a_{0} C_{T} e^{-E /(R T)} \\
\frac{d N_{s}}{d \tau} & =m_{s}\left(a-b N_{s}\right) n
\end{aligned}\right.
$$


where $a_{0}$ - constant; $m_{s}$ - soot particle mass.

The burnup rate of soot for local areas with a low or high ratio of the concentration of soot to oxygen is determined similarly to the burnup rate of fuels:

$$
\frac{d C_{v}}{d \tau}=A \overline{C_{T}} \frac{E}{K}
$$

or

$$
\frac{d C_{v}}{d \tau}=A \frac{C_{O_{2}} E \overline{C_{v}} L_{0}}{L_{S} K\left(\overline{C_{v}} L_{S}+C_{T} L_{0}\right)},
$$

where $\overline{C_{v}}$ - time-average mass concentration of soot; $L_{s}$ - stoichiometric coefficient of soot.

The general kinetics of the soot formation process is described by equations (2.1) and (2.2). These equations allow you to calculate the soot yield during combustion. Formulas (2.4)-(2.9) form a system of equations for calculating the soot yield in a turbulent flow [15-19].

To solve problems in order to obtain certain grades of soot, it is necessary to take into account the change in the size distribution function of soot particles. For this, another method of modeling the soot formation process is considered, in which an analysis is carried out using the formulas of formal chemical kinetics for each separate act of the addition of carbon molecules to radicals - the nucleus and particles of a new phase. In this case, the source of carbon molecules can be both initial and intermediate hydrocarbons, and active particles [20].

Model of soot formation taking into account kinetics:

$$
A_{0} \stackrel{x_{0}}{\rightarrow} A_{1}, A_{i}+A_{0} \stackrel{k_{i}}{\rightarrow} A_{i+1}, A_{i}+A_{j} \stackrel{k_{i j}}{\rightarrow} A_{i+j}, 0<i<\infty, 0<j \leq 3
$$

where $k_{i}$ and $k_{i j}$ - reaction rate constants; $A_{0}$ - starting hydrocarbon molecule; $A_{i}$ - a particle containing $2 i-$ carbon atoms.

An alternative approach considers: monomolecular decomposition of the initial hydrocarbon, which occurs with the formation of active particles; bimolecular reaction of interaction of active particles with a hydrocarbon with subsequent growth of particles; upon collision with soot particles, the death of active centers is considered [21, 22].

In the model of soot formation (2.10), the reactions are written in general form. The given model is described by a system of equations of the form:

$$
\left\{\begin{array}{c}
\frac{d N_{0}}{d \tau}=-k_{0} N_{0}-\sum_{j=1}^{\infty} k_{j} \\
\frac{d N_{0}}{d \tau}=k_{0} N_{0}-k_{1} N_{1} N_{0}-k_{11} N_{1}^{2}-\sum_{j=1}^{\infty} k_{j i} N_{1} N_{j} \\
\frac{d N_{2}}{d \tau}=k_{1} N_{1} N_{0}-k_{2} N_{2} N_{0}-k_{11} N_{1}^{2}-k_{22} N_{2}^{2}-\sum_{j=1}^{\infty} k_{2 j} N_{2} N_{j} \\
\frac{d N_{3}}{d \tau}=k_{2} N_{2} N_{0}-k_{3} N_{3} N_{0}-k_{12} N_{1} N_{2}-k_{33} N_{3}^{2}-\sum_{j=1}^{3} k_{i j} N_{3} N_{j} \\
\frac{d N_{i}}{d \tau}=k_{i-1} N_{i-1} N_{0}-k_{i} N_{i} N_{0}+\sum_{j=1}^{3} k_{i-j} N_{i-j} N_{j}-\sum_{j=1}^{3} k_{i j} N_{2} N_{j}
\end{array}\right.
$$

where $N_{0}$ - mass concentration of the initial hydrocarbon per unit volume of combustion products.

In reality, the number of equations is infinite. However, in practice (2.11) are limited by the number of carbon atoms in the particle. The system of equations (2.11) must be supplemented with the equations of heat and mass transfer and the chemical kinetics of the fuel burnout process [23, 24]. 


\section{Results and discussion}

\subsection{Formation of soot during combustion of premixed fuel mixtures}

The mass concentration of soot during the combustion of high-calorie hydrocarbon mixtures has a wide range of the recorded parameter. Therefore, for example, the concentration of soot under different conditions differ by 3-4 orders of magnitude.

In the numerical experiment, the settling surface method was used. This method is the simplest. It consists in the following for deposition, a metal surface cold in relation to the combustion products is used. The disadvantage of the deposition method is the effect of the cold body on the flame and on the soot formation process. This leads to distortion of the experimental results.

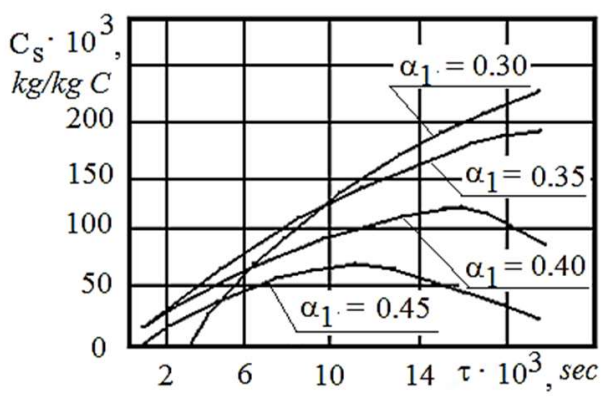

Fig. 2. Dependence of the mass yield of soot on the residence time and the excess air ratio: $W_{l}=6.5 \mathrm{~m} / \mathrm{sec} ; p=2.45 \mathrm{MPa} ; T_{0}=573 \mathrm{~K}$.

The influence of some parameters on the concentration of soot in the working fluid is considered. The initial air temperature $T_{0}$ and the initial temperature of the homogeneous airfuel mixture Fig. 2 have a significant effect on the soot yield. An increase in the temperature of the mixture leads to a shift in the gust of formation of soot $\alpha_{s}$ in the direction of enriching the mixture with fuel and to an increase in the yield of soot at $\alpha_{1}=0.3 \ldots 0.43$. In the range of values $\alpha_{1}=0.43 \ldots 0.55$, which is directly adjacent to the soot formation threshold, an increase in the mixture temperature and flame temperature leads to a decrease or elimination of the soot yield.

Fig. 3 shows the dependence of the concentration of soot in the combustion products on the residence time at various values of the excess air ratio.

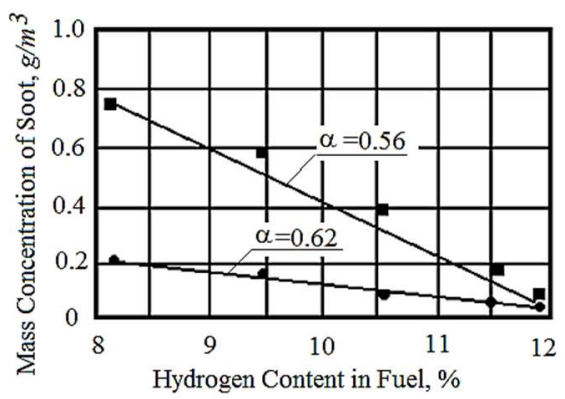

Fig. 3. Dependence of the mass concentration of soot per unit volume of the combustion product on the hydrogen content in the fuel for mixtures. 
The intensity of soot formation during combustion depends on the quantitative composition of the fuel. The fuel can be both construction waste and waste from medical enterprises or organizations associated with the chemical industry, etc. Various options for waste disposal power plants are considered. For each power plant in the combustion chamber, depending on the design features, its own type of flame is characteristic. Revealing the universal mechanism of the soot formation process through the use of individual various hydrocarbons is a priority task. It is necessary to establish the influence of the fuel composition on the level of smoke to predict the release of soot and take into account the impact on the ecosystem.

The results of the obtained numerical studies indicate the dependence of the yield of dispersed carbon in various types of flame on the composition of the fuel. The main parameter of the fuel is the hydrogen content and the quantitative characteristic of the ratio of hydrogen to carbon $\mathrm{H} / \mathrm{C}$. When some individual hydrocarbons are burned with air, with an increase in the $\mathrm{H} / \mathrm{C}$ ratio, the soot yield is significantly reduced. The composition of the fuel composition has an effect on the output of soot during combustion, provided that the $\mathrm{H} / \mathrm{C}$ ratio is constant. For multicomponent fuels, the percentage of aromatic hydrocarbons in them is taken into account. This is due to the difference in the mechanisms of soot formation during the combustion of aromatic hydrocarbons. The more aromatic hydrocarbons in the composition, the higher the soot yield.

\section{Conclusions}

The obtained results of a numerical study indicate the influence of various factors on the quantitative characteristics of soot formation. Assumption: we neglect heat losses from the combustion zone. The calculation is carried out for conditions of constant pressure. The soot formation boundary is shifted to the area of leaner mixtures. Calculations showed that in the presence of heat loss, soot is released, and at certain values of $\alpha 1$, soot formation will occur under conditions when the pressure is not constant.

All characteristics of soot formation must be considered. Focus is on the conditions of high heat loss in the reaction zone. Heat loss can be associated with a high level of radiative heat transfer from the soot plume to the walls of the flame tube. The qualitative nature of the effect of heat removal and heat supply on the release of soot in the flame of a homogeneous mixture of different initial composition coincides with the nature of the effect of the initial temperature of the mixture.

Heat loss from the reaction zone leads to a decrease in the yield of soot for rich mixtures.

The performed computational studies confirm that the formation of soot is not a stable characteristic of hydrocarbon fuel and does not depend on the temperature conditions in the reaction zone.

\section{References}

1. M. Edo, N. Ortuño, P.E. Persson, J.A. Conesa, S. Jansson, Chemosphere (2018). DOI: 0.1016/j.chemosphere.2018.03.203.

2. H. Wu, Q. Wang, J.H. Ko, Q. Xu, Waste Manag (2018). DOI: 10.1016/j.wasman. 2018.05.032.

3. C. Mersoni, G.A. Reichert, Eng. Sanit. e Ambient (2017). DOI: 10.1590/S141341522017150351.

4. Z.T. Yaqub, B.O. Oboirien, A.T. Akintola, J. Mater. Cycles Waste Manag. (2021). DOI: 10.1007/s10163-021-01180-0. 
5. H.S. Chua, M.J.K. Bashir, K.T. Tan, H.S. Chua, AIP Conf. Proc. (2019).

6. A.R. Khoso, A.H. Memon, A.A. Pathan, M.A. Akhund. Mehran Univ. Res., J. Eng. Technol (2018). DOI: 10.22581/muet1982.1803.18.

7. Z. Cheng, S. Zhu, X. Chen, L. Wang, Z. Lou, L. Feng, J. Hazard. Mater. (2020). DOI: 10.1016/j.jhazmat.2019.120912.

8. W. Yan, C. Lou, Q. Cheng, P. Zhao, X. Zhang, Appl. Sci. (2017). DOI: 10.3390/app7030263.

9. R. Jin, J. Zhan, G. Liu, Y. Zhao, M. Zheng, L. Yang, M. Wang, Chemosphere (2017). DOI: $10.1016 /$ j.chemosphere.2017.01.115.

10. W. de Matos Firmino Silva, D. Imbrosi, J.M. Nogueira, Curr. Urban Stud. (2017). DOI: $10.4236 /$ cus.2017.52011.

11. H.P. Huang, Q. Hu, Z.P. Wang, X.Z. Qiao, H. Shu, H. Chen, Z.Z. Yang, Zhongguo Huanjing Kexue/China Environ. Sci. (2018).

12. J. Li, S. Zhang, Q. Wang, W. Ni, K. Li, P. Fu, W. Hu, Z. Li, J. Hazard. Mater. (2020). DOI: 10.1016/j.jhazmat.2020.123191.

13. A. Ramos-Ruiz, J.A. Field, W. Sun, R. Sierra-Alvarez, Waste Manag. (2018). DOI: 10.1016/j.wasman.2018.04.027.

14. Y. Liu, N.M. Robey, J.A. Bowden, T.M. Tolaymat, B.F. Da Silva, H.M. Solo-Gabriele, T.G. Townsend, Environ. Sci. Technol. Lett. (2021). DOI: 10.1021/acs.estlett.0c00819.

15. O. Barysheva, R. Sadykov, IOP Conf. Ser. Mater. Sci. Eng. (2020).

16. R. Zhong, C. Wang, Z. Zhang, Q. Liu, Z. Cai, Waste Manag. (2020). DOI: 10.1016/j.wasman.2020.03.020.

17. R. Rajapriya, V. Murugaiyan, Pollut. Res. (2017).

18. A.F. Dregalin, O.B. Barysheva, A.S. Cherenkov, Russ. Aeronaut. (2007). DOI: 10.3103/S1068799807030117.

19. J.H. Ko, Q. Wang, T. Yuan, H. Wu, Q. Xu, Sci. Total Environ. (2019). DOI: 10.1016/j.scitotenv.2019.06.119.

20. O. Barysheva, R. Sadykov, Y. Khabibullin, E. Zheltukhina, E3S Web Conf. (2019).

21. C. Mersoni, G.A. Reichert, Eng. Sanit. e Ambient. (2017). DOI: 10.1590/s141341522017150351.

22. H. Luo, D. He, W. Zhu, Y. Wu, Z. Chen, E.H. Yang, Waste Manag. (2019). DOI: 10.1016/j.wasman.2018.11.037.

23. J. Lee, D. Choi, Y.F. Tsang, J.I. Oh, E.E. Kwon, Environ. Pollut. (2017). DOI: 10.1016/j.envpol.2017.02.028.

24. G. Akhmerova, A. Zalyalova, R. Mukhametshina, IOP Conf. Ser. Mater. Sci. Eng. (2020). 